\title{
Temporal and seasonal variation in the occurrence of chemical incidents
}

\author{
B Olowokure, P J Saunders, J A Dyer, A J Kibble
}

Occup Environ Med 2004;61:177-179

\begin{abstract}
Aims: To determine whether there were temporal or seasonal patterns in the occurrence of chemical incidents reported to the West Midlands Chemical Incident Surveillance System, UK.

Methods: A retrospective analysis of reports maintained on a computerised database was carried out for information received from January 1997 to December 2001.

Results: Annual numbers of events increased significantly from $77(7.5 \%)$ in 1997 to $282(27.4 \%)$ in 2001 . Compared to the average of other seasons, proportionately more incidents occurred in the summer (29.3\%). Compared with the average of other days, incidents were more likely to occur on Thursdays (17.1\%) and least likely on Saturdays (8.9\%). When grouped together on a six hourly basis incidents were most frequent between 1200 and $1759(31.1 \%)$ and least frequent between 0000 and 0559 (21.2\%).

Conclusions: The surveillance system shows that chemical incidents do not occur randomly but have marked temporal and seasonal variation. These results have implications for service provision, training, and the development of preventive strategies.
\end{abstract}

$\mathrm{T}$ here has been growing concern regarding the potential for chemicals to cause harm to human health and the environment. The numbers and volumes of chemicals in production has increased, ${ }^{1}$ and the need to transport them from one geographical area to another means that individuals and populations are potentially at risk. This is because chemical incidents resulting in potentially adverse public health effects may occur anywhere and at anytime. In the West Midlands region, UK, the Chemical Hazard Management and Research Centre (CHMRC) has provided a 24 hour response service for the management of incidents involving chemical or other materials potentially hazardous to the health of human populations since 1996. The CHMRC has been involved in chemical incident management and surveillance for several years and participates in active regional and national incident surveillance. The objective of this study was to determine whether there were discernible patterns in the occurrence of chemical incidents reported to the West Midlands Chemical Incident Surveillance System (WMCISS) by time of day, day of the week, month, and season of the year. To achieve this a retrospective analysis of the WMCISS database was carried out from January 1997 to December 2001.

\section{METHODS}

The surveillance system receives reports from a number of sources including the emergency services (particularly the fire service), health authorities (and more recently Primary Care Trusts), the Department of Health and the National
Health Service, local authorities and the Environment Agency, as well as those reported directly to the CHMRC. The CHMRC also routinely reviews press clippings from local and national media. Reports are also received from the National Focus for Chemical Incidents in Cardiff, Wales, and the other chemical incident regional service provider units (RSPUs) in the UK. These reports are maintained on a computerised database that also provides information for the national chemical incident surveillance system organised and operated by the National Focus for Chemical Incidents. A standardised form permits the collection of information in a systematic manner and also allows information to be obtained at a later date if it was not collected during the initial encounter. The database is checked weekly for duplicate reports.

\section{Definitions}

The surveillance system employs definitions developed by the World Health Organisation (WHO) International Programme on Chemical Safety (IPCS) and the National Focus for Chemical Incidents. A chemical incident is defined as "an acute event in which there is, or could be, exposure of the public to chemical substances, which cause, or have the potential to cause ill health". ${ }^{2}$ There are also definitions for the different types of chemical incident. ${ }^{2}$ Briefly, these are: spill-a substance released from an intact container; leaksubstance released from a faulty container; fire-combustion involving chemicals; explosion-violent release of energy from a rapid chemical reaction; release-inappropriate release of a chemical from an identified source not attributable to other types of incident; deposit-chemical substance inappropriately deposited in locations not designated for that purpose. In this survey chemical incidents were classified into five categories: (1) spills and/or leaks; (2) fires and/or explosions; (3) releases; (4) deposits; (5) other types not classified; and (6) unknown.

\section{Data analysis}

The time factors to be assessed relating to reported chemical incidents were time of occurrence, date, month, and season. To examine seasonal variation we divided the year into four seasons: spring (March-May), summer (June-August), autumn (September-November), and winter (DecemberFebruary). Data analysis was performed using the $\chi^{2}$ test.

Abbreviations: ATSDR, Agency for Toxic Substances and Disease Registry; CHMRC, Chemical Hazard Management and Research Centre; HSEES, Hazardous Substances Emergency Event Surveillance System; IPCS, International Programme on Chemical Safety; RSPUs, regional service provider units; WHO, World Health Organisation; WMCISS, West Midlands Chemical Incident Surveillance System 


\section{Main messages}

- There has been a significant increase in the number of chemical incidents reported since 1997.

- A high proportion of chemical incidents occur during the summer months.

- Incidents are most likely to occur mid-week.

- Almost $50 \%$ of incidents occurred "out of hours".

\section{RESULTS}

Altogether, 1029 chemical incidents were reported during the five year study period (table 1). As a proportion of the total number of incidents, there were significantly more $(p<0.0001)$ incidents in 2001 compared with the 1997 baseline. In addition, although the number of events for each category increased from the 1997 baseline (table 1), the proportion attributable to each incident category remained relatively stable. Table 1 shows the distribution of incidents within the five incident types. Compared with the average of other known incident types, spills/leaks were the most common incident reported $(34.5 \% ; \mathrm{p}<0.0001)$ and releases the least commonly reported $(8.5 \% ; \mathrm{p}<0.0001)$. The incident type could not be determined for 55 reports.

Analysis by month indicated that when compared with the monthly average of all reported incidents, most incidents occurred in July $(110 / 1029,10.7 \% ; p=0.041)$ and the fewest in December $(51 / 1029,5.0 \% ; p=0.0012)$. When examined by season (table 1), significant seasonal variation was identified. Compared to the average of other seasons, most incidents occurred in the summer months $(29.3 \% ; \mathrm{p}=0.032)$ and fewer in winter $(20.6 \%$; $\mathrm{p}=0.0015)$.

Table 1 shows day of the week variation, with weekends having the lowest number of reported incidents. Compared with the average of the other days, incidents were most frequent on Thursdays $(17.1 \% ; \mathrm{p}=0.038)$ and least frequent on Saturdays $(8.9 \% ; \mathrm{p}<0.0001)$ or Sundays $(10.0 \%$; $\mathrm{p}<0.001)$.

Overall, 489 (47.5\%) incidents were reported outside the normal working day (taken to be 0 00-17 59). When grouped on a six hourly basis incidents were most frequent between 1200 and 1759 (31.1\%; p<0.0001) and least frequent between 0000 and 0559 (20.9\%; p = 0.018).

\section{DISCUSSION}

These results reveal a steady increase in reported chemical incidents over the five year study period. A higher occurrence of chemical incidents in the summer, during the middle of the week, and between the hours of 1200 and 1759 was also identified.

The increasing number of reported incidents seen over the five year study period may be due to a number of factors acting individually or collectively, including increased use of the service or improved surveillance. The latter may explain the large increase from 1997 to 1998 and the more gradual increase thereafter, as well as the reduction in the number of unclassified chemical incidents.

The finding that 19\% of incidents occurred at the weekend mirrors that reported by the Agency for Toxic Substances and Disease Registry (ATSDR), USA. ${ }^{3}$ The ATSDR also reported that approximately $31 \%$ of incidents occurred between 1200 and 18 ?00, again consistent with our results over the same time period. Although the ATSDR report did not examine seasonality, a recent report from the Hazardous Substances Emergency Event Surveillance system (HSEES), which is maintained by the ATSDR, has described a seasonal association. ${ }^{4}$ The authors report an increasing number of chemical
Policy implications

- There is a need for continuing out of hours service provision.

- Targeted training for public health professionals is required.

- Results may be used to develop preventive strategies.

incidents occurring between April and June in four midWestern states of the USA. This observation is not unexpected as this period corresponds to the planting season in these states, and the report concentrated on chemical incidents related to the agricultural industry.

The differences observed in the occurrence of chemical incidents between the weekend and weekdays in the West Midlands could plausibly be explained by population activity patterns. Less industrial activity and transport of hazardous materials over the weekend may reduce the potential for a chemical incident. Similarly, the monthly and seasonal patterns observed may also be explained by variations in activity levels, with outdoor activity increasing in the summer months as a result of increased daylight hours and better weather.

A previously published report from Wales evaluated surveillance for community exposure to acute chemical incidents over a three year period up to $1995 .{ }^{5}$ However, the researchers did not examine temporal or seasonal variation in the occurrence of chemical incidents. To our knowledge this is the first population based UK report describing temporal and seasonal variation in chemical incident occurrence.

The data and the methodology presented here are subject to a number of limitations, particularly those associated with passive surveillance systems. For example, although the WMCISS employs several overlapping reporting sources, including the CHMRC, in order to ensure that as many incidents as possible are identified, a number of chemical incidents may not be reported. Furthermore, although the database provides a frequency count of chemical incidents, lack of denominator data limits the conclusions that can be drawn. Additionally, environmental factors and demographic details are not routinely reported, thereby making it difficult to ascertain the cause of an event or its impact on the health of the population.

Despite these limitations the results presented have important implications for service provision and training of public health professionals. For example, in the UK the recently proposed revision of the health protection function places increased responsibility for the management of acute chemical incidents on public health professionals. ${ }^{6}$ However, many public health professionals lack the expertise and knowledge required..$^{7}$ The implications for training public health professionals follow from identification of the periods when chemical incidents are most likely to occur. After appropriate training, "out of hours" experience can provide further opportunities to gain, and maintain, knowledge and expertise in dealing with acute chemical incidents. With regard to service provision, since $48 \%$ (489/1029) of incidents in this study occurred "out of hours", the results support the need for this type of service. Our results could also be used for the provision and planning of such a service in areas where it is not yet available.

The results of this study suggest that although chemical incidents may occur at any time, they are not random events but appear to occur in temporal and seasonal patterns. Further investigation is required to identify causes of this 
Table 1 Temporal and seasonal occurrence of chemical incidents in the West Midlands region, UK: 1997-2001

\begin{tabular}{|c|c|c|c|c|c|c|c|}
\hline & \multicolumn{7}{|c|}{ Type of chemical incident reported, $\mathrm{n}(\%)$} \\
\hline & Deposit & Spill/leak & Fire/explosion & Releases & Other & Unknown & Total \\
\hline All events & 85 & 355 & 340 & 87 & 107 & 55 & 1029 \\
\hline \multicolumn{8}{|l|}{ Study year } \\
\hline 1997 & $2(2.4)$ & $23(6.5)$ & $17(5.0)$ & $5(5.7)$ & $9(8.4)$ & $21(38.2)$ & $77(7.5)$ \\
\hline 1998 & $17(20.0)$ & $60(16.9)$ & $50(14.7)$ & $19(21.8)$ & $7(6.5)$ & $9(16.4)$ & $162(15.7)$ \\
\hline 1999 & $13(15.3)$ & $81(22.8)$ & $64(18.8)$ & $24(27.6)$ & $30(28.0)$ & $10(18.2)$ & $222(21.6)$ \\
\hline 2000 & $30(35.3)$ & $91(25.6)$ & $117(34.4)$ & $16(18.4)$ & $23(21.5)$ & $9(16.4)$ & 286 (27.8) \\
\hline 2001 & $23(27.1)$ & $100(28.2)$ & $92(27.1)$ & $23(26.4)$ & $38(35.5)$ & $6(10.9)$ & $282(27.4)$ \\
\hline \multicolumn{8}{|l|}{ Season } \\
\hline Spring & $20(23.5)$ & $83(23.4)$ & $89(26.2)$ & $20(23.0)$ & $24(22.4)$ & $16(29.1)$ & 252 (24.5) \\
\hline Summer & $18(21.2)$ & $104(29.3)$ & $111(32.6)$ & $32(36.8)$ & $29(27.1)$ & $8(14.5)$ & 302 (29.3) \\
\hline Autumn & $28(32.9)$ & $98(27.6)$ & $70(20.6)$ & $18(20.7)$ & 35 (32.7) & $14(25.5)$ & $263(25.6)$ \\
\hline Winter & $19(22.4)$ & 70 (19.7) & 70 (20.6) & 17 (19.5) & 19 (17.8) & 17 (30.9) & 212 (20.6) \\
\hline \multicolumn{8}{|l|}{ Day of the week } \\
\hline Monday & $14(16.5)$ & 48 (13.5) & 54 (15.9) & $14(16.1)$ & 19 (17.8) & $10(18.2)$ & 159 (15.5) \\
\hline Tuesday & 16 (18.8) & $59(16.6)$ & 44 (12.9) & 12 (13.8) & $23(21.5)$ & $8(14.5)$ & 162 (15.7) \\
\hline Wednesday & 13 (15.3) & $63(17.7)$ & 39 (11.5) & $21(24.1)$ & $24(22.4)$ & $9(16.4)$ & 169 (16.4) \\
\hline Thursday & 13 (15.3) & 68 (19.2) & 59 (17.4) & 12 (13.8) & 13 (12.1) & $11(20.0)$ & 176 (17.1) \\
\hline Friday & $14(16.5)$ & 62 (17.5) & $52(15.3)$ & 14 (16.1) & 14 (13.1) & $12(21.8)$ & 168 (16.3) \\
\hline Saturday & $7(8.2)$ & $27(7.6)$ & $40(11.8)$ & $8(9.2)$ & $7(6.5)$ & $3(5.5)$ & $92(8.9)$ \\
\hline Sunday & $8(9.4)$ & $28(7.9)$ & $52(15.3)$ & $6(6.9)$ & $7(6.5)$ & $2(3.6)$ & $103(10.0)$ \\
\hline \multicolumn{8}{|c|}{ Time of day ( 6 hourly) } \\
\hline $0000-0559$ & $11(12.9)$ & $55(15.5)$ & $62(18.2)$ & $35(40.2)$ & 35 (32.7) & $20(36.4)$ & 218 (21.2) \\
\hline $0600-1159$ & $17(20.0)$ & $104(29.3)$ & $68(20.0)$ & $23(26.4)$ & $29(27.1)$ & $12(21.8)$ & $253(24.6)$ \\
\hline $1200-1759$ & $33(38.8)$ & $118(33.2)$ & $102(30.0)$ & $21(24.1)$ & $29(27.1)$ & $17(30.9)$ & $320(31.1)$ \\
\hline $1800-2359$ & $24(28.2)$ & $78(22.0)$ & $108(31.8)$ & $8(9.2)$ & $14(13.1)$ & $6(10.9)$ & $238(23.1)$ \\
\hline
\end{tabular}

variation and utilise the information obtained to develop and implement preventive strategies.

\section{Authors' affiliations}

B Olowokure, P J Saunders, Department of Public Health and Epidemiology, University of Birmingham, UK

J A Dyer, A J Kibble, Chemical Hazard Management and Research Centre, Division of Environmental Health and Risk Management, University of Birmingham, UK

Correspondence to: $\mathrm{Dr}$ B Olowokure, PHLS Communicable Disease Surveillance Centre (West Midlands), 2nd Floor, Lincoln House, Heartlands Hospital, Birmingham B9 5SS, UK;

bolowokure@cdscwmid.demon.co.uk

Accepted 27 March 2003

\section{REFERENCES}

1 United Nations Environmental Programme. Chemical pollution: a global overview. Geneva: The International Register of Potentially Toxic Chemicals and The Global Environmental Monitoring and Assessment Research Centre, 1992.

2 National Chemical Incident Surveillance Steering Group. National public health surveillance of chemical incidents: Results for the pilot phase of the national surveillance scheme April 1998-March 1999. Cardiff: National Focus 1999. Available at: http://www.natfocus.uwic.ac.uk/surveillance/ surv_cu/surv.htm (accessed 27 February 2003).

3 Agency for Toxic Substances and Disease Registry. Hazardous Substances Emergency Events Surveillance (HSEES). Annual Report 1998. Atlanta: US Department of Health and Human Services, 1998, Available at:

www.atsdr.cdc.gov/HS/HSEES/annual98.htm (accessed 29 April 2002)

4 Berkowitz Z, Orr MF, Kaye WE, et al. Hazardous Substances Emergency Events in the agriculture industry and related services in four Mid-Western states. J Occup Environ Med 2002;44:714-23.

5 Bowen HJ, Palmer SR, Fielder HMP, et al. Community exposures to chemical incidents: development and evaluation of the first environmental public health surveillance system in Europe. J Epidemiol Community Health 2000;54:870-3.

6 Department of Health. Getting ahead of the curve: a strategy for combating infectious diseases (including other aspects of health protection). London: Department of Health, 2002

7 Ayres PJ. Major chemical incidents-a response, the role of the consultant in communicable disease control and the case of need for a national surveillance-resource centre. J Public Health Med 1995;17:164-70.

8 Gunnell DJ. The public health physician's role in chemical incidents. J Public Health Med 1993;15:352-7. 